\title{
Unified Analytical Approaches for Determining Shear Bond Characteristics of FRP-Concrete Interfaces through Pullout Tests
}

\author{
Jianguo Dai ${ }^{1}$, Tamon $\mathrm{Ueda}^{2}$ and Yasuhiko Sato $^{3}$
}

Received 22 April 2005, accepted 25 October 2005

\begin{abstract}
The pullout test is a conventional test method for calibrating interfacial shear bond characteristics of Fiber Reinforced Polymer (FRP)-concrete interfaces. However, due to the small bending stiffness of FRP sheets/strips and the highly non-linear interface fracturing mechanism, a well-recognized analytical approach to the accurate interpretation of the pullout test results remains to be achieved despite extensive studies particularly when the aim is to calibrate a local bond stress-slip model, which is necessary for developing bond strength and anchorage length models avoiding the use of empirical formulations. This paper introduces a newly developed non-linear bond stress-slip model for analyzing full-range strain distributions in FRP and shear bond stress distributions in the interface bond layer during pullout tests, along with a new anchorage length model and bond strength model that were developed accordingly. Compared with other existing bond models, the bond model described here has two advantages besides its simplicity: (1) it incorporates the most important interface parameter, the so-called interfacial fracture energy, in all analytical processes and links it successfully with all other important bond parameters; (2) it is a general and unified approach that allows for the first time consideration of the effects of the adhesive bond layer in non-linear analysis of FRP-concrete interfaces. Further, a unified bond stress versus slip expression is formulated to show the differences in local bond stress-slip relationships at the loaded and free ends in pullout tests, so that the effects of the bond length used in a pullout test on the calibration of the interfacial bond stress-slip model can be clarified. The reliability of all proposed models is verified through a comprehensive comparison of the experimental and analytical results.
\end{abstract}

\section{Introduction}

Bonding FRP sheets/strips externally to existing RC members has been studied widely for the purpose of flexural strengthening, shear strengthening, seismic retrofitting and other engineering applications. In flexural and shear strengthening cases, debonding between concrete and externally bonded FRP usually corresponds with the ultimate limit states of retrofitted RC members. This premature debonding either decreases the strength efficiency of FRP materials or causes a deficiency in member ductility. Interface debonding failure modes in various strengthening cases have been carefully classified and documented (Buyukozturk and Hearing 1998, Triantafillou 1999, fib 2001, Sebastian 2001, Smith and Teng 2002, Buyukozturk, et al. 2004). Analytical models also have shown quantitatively how the interface bond strength or local bond stress-slip property influences peak flexural or shear strength of RC members retrofitted with FRP externally (Khalifa et al. 1998, Kamiharako et al. 2001, Yokota 2002, Chen and Teng 2003, Teng et al.

\footnotetext{
${ }^{1}$ Researcher, Life Cycle Management Research Center, Port and Airport Research Institute, Japan.

E-mail: dai@pari.go.jp

${ }^{2}$ Professor, Division of Built Environment, Hokkaido University, Japan.

${ }^{3}$ Associate Professor, Division of Built Environment, Hokkaido University, Japan.
}

2003, Wu and Yin 2003). Due to the important roles of interface bond in maintaining the composite performances of retrofitted members, the interface properties of FRP externally bonded to concrete should be studied extensively from both mechanical and durability viewpoints (Buyukozturk et al. 2004). Many researchers have applied direct pullout tests to evaluate overall and local bond characteristics of FRP-concrete joints subjected to shear (Chajes et al. 1996, Täljsten 1997, Neubauer and Rostásy 1997, Sato et al. 1997, Maeda et al. 1997, Bizindavyi and Neale 1999, Brosens and Van Gemert 1999, Miller et al. 1999, Sato et al. 2000, Yoshizawa et al. 2000, Lorenzis et al. 2001, Nakaba et al. 2001, Kanakubo 2003, Santos 2003, Dai and Ueda 2003, Yao et al. 2004, Xiao et al. 2004). This broad array of studies gave birth to various bond strength, anchorage length and local bond stress-slip models (see the review in Chen and Teng 2001, Teng et al. 2004). The accumulation of experimental databases makes it possible to improve bond strength prediction at an average level (Teng et al. 2004). It is interesting to note, however, that this array of studies did not succeed in achieving a well-recognized but easily applicable analytical approach for calibrating all desired bond characteristics of FRP-concrete interfaces through conventional pullout tests. This is probably due to the following difficulties:

1: Difficulty in capturing brittle but highly non-linear local interface fracture through observation of local strain information of FRP in pullout tests. The interface 
Table 1 Bond Strength and Effective Bond Length Models Based on Different $\tau \sim s$ Relationships.

\begin{tabular}{|c|c|c|c|}
\hline Authors & $\tau \sim \mathrm{s}$ Model & $\begin{array}{l}\text { Expression for effective bond } \\
\text { length }\end{array}$ & Bond strength model \\
\hline $\begin{array}{l}\text { Kanakubo et al. } \\
\text { (2003) }\end{array}$ & $\begin{array}{l}\text { Popovics } \\
\text { expression }\end{array}$ & $L_{e}=0.7 \sqrt{\frac{E_{f} t_{f}}{f_{c}^{0.2}}}$ & $\begin{array}{c}P_{u}=1.1 f_{c}^{.0 .2} b_{f} L_{e}\left(L_{b}>L_{e}\right) \\
P_{u}=\left\{0.7 \cos \left(\frac{L_{b}}{L_{e}}\right) \pi+1.8\right\} f_{c}^{, 0.2} b_{f} L_{b}\left(L_{b}<L_{e}\right)\end{array}$ \\
\hline $\begin{array}{l}\text { Chen and Teng } \\
\text { (2001) }\end{array}$ & unknown & $L_{e}=\sqrt{\frac{E_{f} t_{f}}{\sqrt{f_{c}^{\prime}}}}$ & $\begin{array}{c}P_{u}=0.427 \beta_{w} \beta_{L} \sqrt{f_{c}^{\prime}} b_{f} L_{e} \\
\beta_{w}=\sqrt{\frac{2-b_{f} / b_{c}}{1+b_{f} / b_{c}}} \\
\beta_{L}=1\left(L_{b} \geq L_{e}\right), \beta_{L}=\sin \frac{\pi L_{b}}{2 L_{e}}\left(L_{b}<L_{e}\right)\end{array}$ \\
\hline Sato et al. (1997) & $\begin{array}{l}\text { Elasto- } \\
\text { plastic }\end{array}$ & $45 \mathrm{~mm}$ & Not proposed \\
\hline $\begin{array}{l}\text { Lorenzis et al. } \\
\quad(2001)\end{array}$ & $\begin{array}{l}\text { Elasto- } \\
\text { plastic }\end{array}$ & $100 \mathrm{~mm}$ & Not proposed \\
\hline Sato et al. (2001) & $\begin{array}{l}\text { Shear } \\
\text { softening }\end{array}$ & $L_{e}=1.89\left(E_{f} t_{f}\right)^{0.4}$ & $\begin{array}{c}P_{u}=5.06 f_{c}^{0.2}\left(E_{f} t_{f}\right)^{1.4}\left(b_{f}+2 \Delta b_{f}\right) L_{b} \times 10^{-5} \\
E_{f} t_{f}<38.4 \mathrm{kN} / \mathrm{mm} \\
P_{u}=1.95 f_{c}^{\prime 0.2}\left(E_{f} t_{f}\right)^{0.4}\left(b_{f}+2 \Delta b_{f}\right) L_{b} \times 10^{-5} \\
E_{f} t_{f}>38.4 \mathrm{kN} / \mathrm{mm}\end{array}$ \\
\hline $\begin{array}{l}\text { Yoshizawa et al. } \\
\quad(2000) \text { and } \\
\text { Yuan } \text { et al. }(2001)\end{array}$ & Bilinear & $\begin{array}{c}L_{e}=a_{0}+\frac{1}{2 \lambda_{1}} \ln \frac{\lambda_{1}+\lambda_{2} \tan \left(\lambda_{2} a_{0}\right)}{\lambda_{1}-\lambda_{2} \tan \left(\lambda_{2} a_{0}\right)} \\
a_{0}=\frac{1}{\lambda_{2}} \sin ^{-1}\left(0.97 \sqrt{\frac{\delta_{f}-\delta_{1}}{\delta_{f}}}\right) \\
\lambda_{1}^{2}=\frac{\tau_{\max }}{\delta_{1} E_{f} t_{f}} \\
\lambda_{2}^{2}=\frac{\tau_{\max }}{\left(\delta_{f}-\delta_{1}\right) E_{f} t_{f}}\end{array}$ & $\begin{array}{c}P_{u}=\frac{\tau_{\max } b_{f}}{\lambda_{2}} \cdot \frac{\delta_{f}}{\delta_{f}-\delta_{1}} \sin \left(\lambda_{2} a\right) \\
\text { where } a \text { is from the equation: } \\
\tanh \left[\lambda_{1}\left(L_{b}-a\right)\right]=\frac{\lambda_{2}}{\lambda_{1}} \tan \left(\lambda_{2} a\right) \\
\tau_{\max }=8.0 \mathrm{MPa}, \delta_{1}=0.05 \mathrm{~mm} \\
\delta_{f}=0.3 \mathrm{~mm}\end{array}$ \\
\hline $\begin{array}{l}\text { Neubauer and } \\
\text { Rostásy (1997) }\end{array}$ & Bilinear & $L_{e}=\sqrt{\frac{E_{f} t_{f}}{2 f_{t}}}$ & $\begin{array}{c}P_{u}=0.64 k_{p} b_{f} \sqrt{E_{f} t_{f} f_{t}}\left(L_{b} \geq L_{e}\right) \\
P_{u}=0.64 k_{p} b_{f} \sqrt{E_{f} t_{f}} \frac{L_{b}}{L_{e}}\left(2-\frac{L_{b}}{L_{e}}\right)\left(L_{b}<L_{e}\right) \\
k_{p}=\sqrt{1.125 \cdot \frac{2-b_{f} / b_{c}}{1+b_{f} / 400}}\end{array}$ \\
\hline
\end{tabular}

of FRP externally bonded to concrete is different from that of reinforcement in concrete. Local bending of externally bonded FRP usually interferes with obtaining correct axial strain information in FRP during pullout tests. Random distribution of coarse aggregates near bond surfaces also makes it difficult to find a unique local bond stress-slip model capable of representing the interface characteristics at all locations. However, without such a model anchorage length and bond strength models can be derived only through the use of empirical formulations, and hence are characterized by lack of generality.

2. Difficulty in incorporating the effects of the adhesive bond layer in calibrating all interface bond characteristics. As a critical factor dominating Mode II (shear) fracturing properties of the FRP-concrete interface (Karbhari and Engineer 1996, Dai and Ueda 2003), the adhesive bond layer naturally affects bond strength and anchorage length, as well as local bond stress-slip behaviors. Unfortunately, it is rarely found that any index in existing bond models can incorporate the adhesives' effects in bond analysis of FRP-concrete interfaces (see Table 1). There being many types of adhesives with different properties available in practical retrofitting engineering, obtaining a unified bond modeling approach even for simple pullout cases is unlikely without introducing appropriate parameters to take into account the properties of adhesives.

3. Difficulty in evaluating concrete surface preparation conditions. The pullout strength of FRP-concrete interfaces is highly sensitive to concrete surface preparation because bond failure always occurs in a thin concrete layer just beneath the adhesive bond layer. Even though a standard concrete surface treatment technology is fol- 
lowed, concrete surface condition may deviate considerably due to differences in the level of operating skills of workers. A good interface parameter to quantify overall interface bond performance is interfacial fracture energy $G_{f}$, since its physical meaning is the area underneath an interfacial bond stress-slip model, but it can be back-calculated from the maximum pullout force (JSCE 2000) by avoiding the difficulty in using local bond stress-slip information, as mentioned above. Plenty of pullout test results accumulated up to now make it possible to evaluate the effects of construction deviations on $G_{f}$ statistically. However, it was pointed out (Sato and Vecchio 2003) that the problem of how to link $G_{f}$ to other interface bond parameters, such as the peak stress, corresponding slip and so on, needs to be further studied.

Regarding analytical work on the pullout performances of FRP-concrete joints, comparatively early works can be found in reports by Taljsten (1996) based on a cut-off type $\tau$-s model and by Brosens and Van Germert (1998) based on a bilinear $\tau$-s model. Yuan et al. (2001), Wu et al. (2002) and Yuan et al. (2004) did further theoretical work showing how to analyze pullout behaviors of FRP-concrete joints in terms of bond strength, effective bond length, and full-range debonding responses mainly based on several assumed types of $\tau$-s models and using interfacial fracture energy. All these analyses indicated how several key bonding parameters such as peak shear bond stress, its corresponding slip value, and the maximum slip corresponding to zero bond stress, affect the bond strength and effective bond length. However, in these investigations, no general approach is given for determining these necessary bonding parameters from pullout tests by overcoming the above-mentioned difficulties. Teng et al (2004) tried to use a mesoscale analytical approach to propose bond-slip models for FRP-concrete pullout joints. This approach is advantageous in helping others observe the debonding mechanisms of FRP-concrete joints more accurately. However, modeling mix-mode concrete cracking behaviors quantitatively at a mesoscale level is too comprehensive to constitute a satisfactory engineering solution. Neglecting the adhesive bond layer in their analysis is also a factor that may affect the reliability of the analysis. Most of all, to successfully calibrating many unknown bonding parameters quantitatively by taking into account the effects of all interfacial material components is hardly an easy proposition, especially when lacking advanced knowledge in numerical simulation. The authors (Dai et al. 2005) proposed an innovative and simple method to derive the local bond stress-slip model of FRP-concrete interfaces from load-slip responses of FRP-concrete joints at the loaded end in a pullout test. Hence, the difficulty in observing local bond information in a pullout test can be avoided. Two simple bond parameters termed interfacial fracture energy $G_{f}$ and interface ductility index $B$, which can be calibrated from conventional pullout tests, are used to formulate a local bond stress-slip model. This work needs to be further elaborated in the discus- sion of development of strain in FRP, bond stress distribution in interface in the whole pullout process and how to use $G_{f}$ and $B$ to develop anchorage length and bond strength models (particularly for short bond length cases). Therefore, solving these pending issues toward an easily applicable but complete analytical process by defining all necessary bond characteristics for FRP-concrete joints based on conventional pullout tests is the main objective of this paper. Further, as very few tests on pullout strength of FRP-concrete interfaces with short bond length have been reported, this paper also provides necessary databases and proposes a unified bond stress-strain-slip model to describe how applied bond length influences the calibration of local bond stress-slip models in pullout tests for FRP-concrete joints.

\section{Derivation of local bond stress-slip model}

\subsection{A simple differential solution}

It is an established technique to obtain the tension-softening diagram of concrete from the load-deflection curve of a notched concrete beam under three-point bending through the $J$-integral method (Li and Ward 1989). In a similar way, the local $\tau \sim S$ constitutive law for an FRP-concrete interface can be obtained from the relationship between pullout load and slip at the loaded point $(P=f(s))$ through simple pullout tests (Dai et al. 2005). During a pullout test for an FRP-concrete interface as shown in Fig. 1, pullout load $P$ in the FRP and slip $s$ between the FRP and the concrete at the loaded point (the circled location in Fig. 1) can be recorded continuously. If FRP stiffness $E_{f} t_{f}$ (product of elastic modulus and thickness of FRP) and bond width $b_{f}$ are known, the relationship between the strain in the FRP and the relative interface slip thus can be obtained as follows:

$$
\varepsilon=f(s)
$$

where $\varepsilon$ and $s=$ FRP strain and interface slip at any a location, respectively.

For FRP externally bonded to concrete, the interfacial bond stress can be written as:

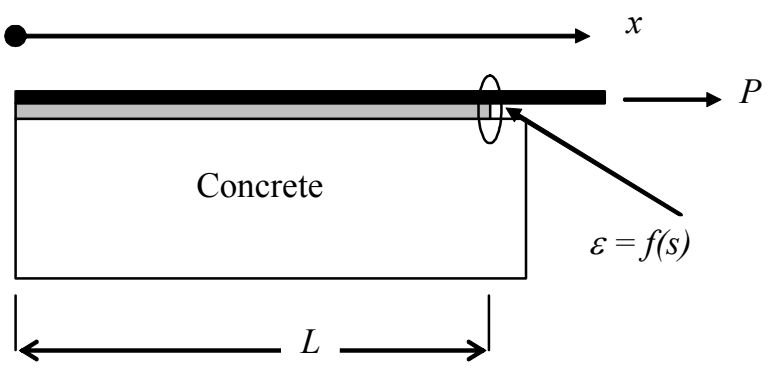

Fig. 1 Sketch of pullout bond test setup. 


$$
\tau=E_{f} t_{f} \cdot \frac{d \varepsilon}{d x}=E_{f} t_{f} \cdot \frac{d f(s)}{d s} \cdot f(s)
$$

because:

$$
\frac{d \varepsilon}{d x}=\frac{d f(s)}{d s} \cdot \frac{d s}{d x}=\frac{d f(s)}{d s} \cdot \varepsilon=\frac{d f(s)}{d s} \cdot f(s)
$$

where $\tau=$ interfacial bond stress.

Using this approach, it is not necessary to get the local $\tau \sim S$ relationship by attaching many gages with a small interval on external bonded FRP to record strain distribution. The effects of coarse aggregates near the interface and local bending of FRP, which are major causes of scatter in the observed FRP strains, can be avoided as well.

\subsection{Derivation of local $\tau \sim s$ model for} FRP-concrete interfaces with long bond length (Dai et al. 2005)

For FRP-concrete interfaces with a bond length longer than $300 \mathrm{~mm}$, various pullout bond tests, in which different types of FRP materials, different adhesives and different FRP stiffness were used, have shown that a unique form of expression as Eq. 4 can represent $f(s)$ in Eq. 1 and fit with the experimental results quite well (Santos et al. 2003, Dai et al. 2005). Figure 2 shows one example.

$$
\varepsilon=f(s)=A(1-\exp (-B s))
$$

With Eq. 2 and Eq. 4, the local $\tau \sim s$ model can be obtained as follows:

$$
\tau=A^{2} B E_{f} t_{f} \exp (-B s)(1-\exp (-B s))
$$

The physical meaning of $A$ in Eq. 5 is the maximum strain reached in the FRP when using a long enough bond length in a pullout test. Through Eq. 5 and definition of interfacial fracture energy $G_{f}$, which is the area under-

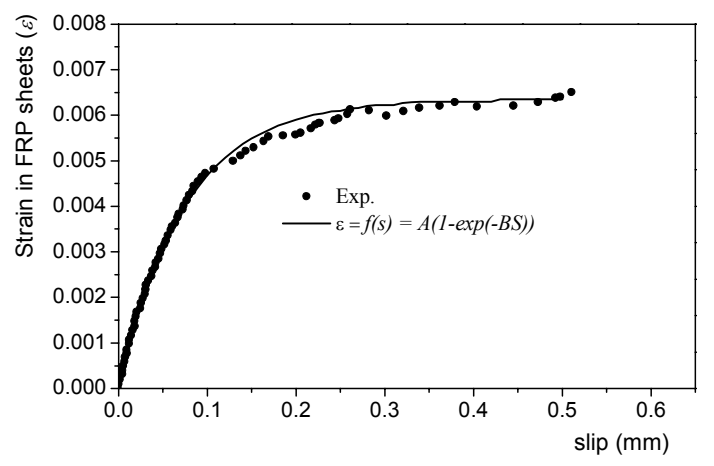

Fig. 2 Typical strain-slip relationship observed in pullout bond tests of FRP-concrete interfaces.

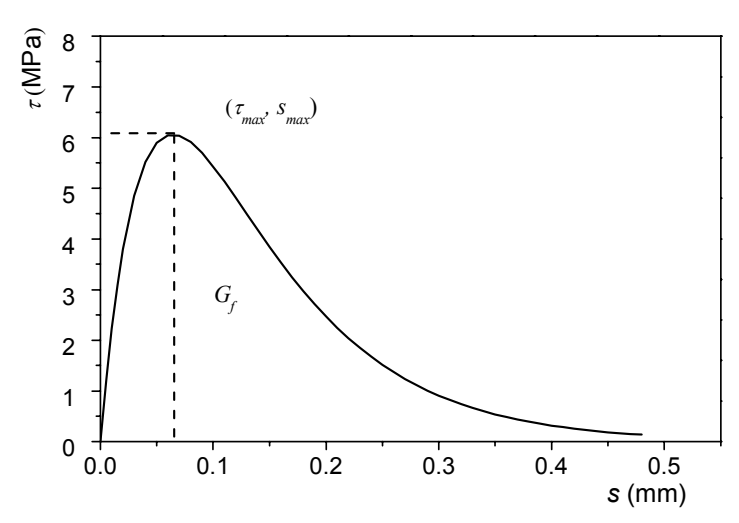

Fig. 3 Shape of proposed $\tau \sim s$ relationship.

neath the local $\tau \sim s$ curve, $\int_{0}^{\infty} \tau d s$, the following expression is obtained:

$$
A=\sqrt{\frac{2 G_{f}}{E_{f} t_{f}}}
$$

Therefore, Eq. 5 can be rewritten substituting Eq. 6 as follows (see the shape of $\tau \sim S$ model in Fig. 3):

$$
\tau=2 B G_{f}(\exp (-B s)-\exp (-2 B s))
$$

where $G_{f}$ is expressed in $[\mathrm{N} / \mathrm{mm}]$ and $B$ in $\left[\mathrm{mm}^{-1}\right]$.

The theoretical maximum bond force for an FRP-concrete interface with sufficiently long bond length is:

$$
P_{\max }=b_{f} \sqrt{2 E_{f} t_{f} G_{f}}
$$

One advantage of the above solution for getting the local $\tau \sim S$ model is its simplicity and rigorous analytical procedure. Another advantage is that parameters like the maximum bond stress and the corresponding slip value (see Fig. 3), which are difficult to calibrate directly from pullout test results, can be determined mathematically as follows:

$$
\begin{gathered}
s_{\text {max }}=0.693 / B \\
\tau_{\max }=0.5 B G_{f}
\end{gathered}
$$

\subsection{Derivation of $\tau \sim \varepsilon \sim s$ model to consider ef- fects of test bond length on local $\tau \sim s$ model}

Local $\tau \sim S$ model of an FRP-concrete interface in Eq. 7 is obtained from the $\varepsilon \sim s$ relationship at the loaded point in a pullout test with long enough bond length, through which the interface can achieve the maximum bond capacity under the boundary condition of zero strain in the FRP 


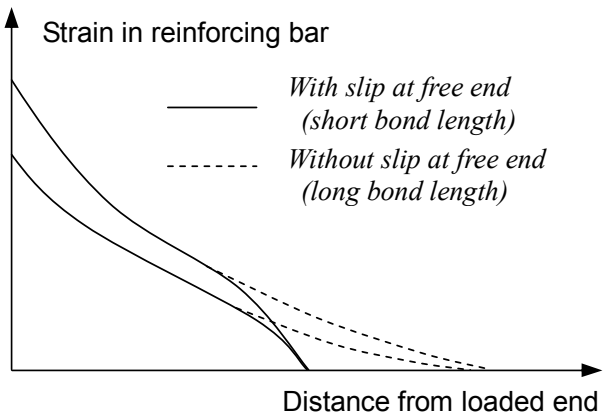

Fig. 4 Strain distributions of reinforcing bar in concrete in a pullout test with or without free end slip.

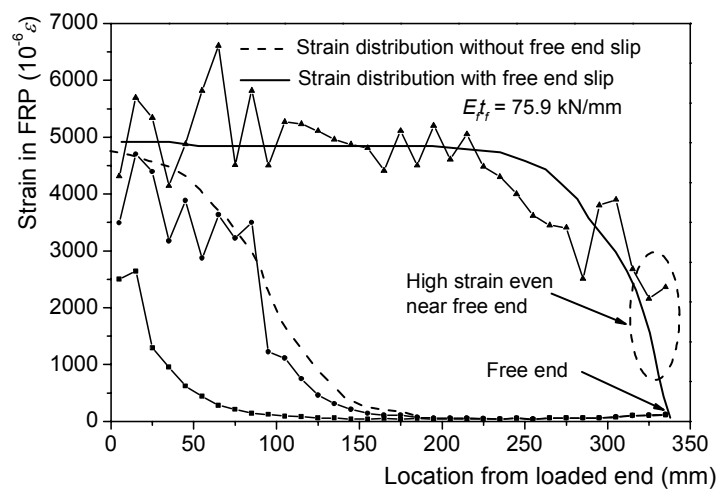

Fig. 5 Observed strain distributions in FRP in a pullout test with or without free end slip.

and zero interface slip at the free end. Under this condition it can be assumed that the $\varepsilon \sim s$ and $\tau \sim S$ relationships are unique or independent of interface locations (Shima et al. 1987). However, when the bond length is short, slip at the free end occurs although strain in the FRP at that location remains zero. Non-zero slip and zero strain at the free end causes different shapes of strain distributions in reinforcing materials internally or externally bonded to concrete (see Fig. 4 and Fig. 5). As a result, $\tau \sim s$ models are considerably different at different locations from the free ends in pullout tests. For reinforcing bar in concrete, Shima et al. (1987) modeled successfully the different $\tau \sim S$ and strain distribution behaviors under three boundary conditions, namely (i) zero bar strain and zero slip at the free end in a pullout test, (ii) zero bar strain and non-zero slip at the free end in a pullout test, and (iii) non-zero bar strain and zero slip at the center position in an axial tension bond test, by including the effects of the reinforcing bar's strain in a $\tau \sim S$ model. Shima et al. concluded that a bond stress-strain-slip $(\tau \sim \mathcal{E} \sim S)$ expression such as the following can be used to unify the $\tau \sim s$ models under all boundary conditions:

$$
\tau=g(\varepsilon) \cdot \tau_{0}(s)
$$

where $\tau_{0}(s)$ is the $\tau \sim s$ relationship under the condition of zero strain in the reinforcing bar, or in other words, at the free end in a pullout bond test, and $g(\varepsilon)$ is a function of the reinforcing bar's strain representing strain effects on $\tau \sim S$ models or reflecting how the boundary conditions in tests influence the obtained local $\tau \sim S$ models.

For FRP externally bonded to concrete, similar bonding mechanisms exist. Before the pullout force reaches the free end of the FRP in a pullout test, the strain distribution in the FRP near the zero strain location shows a smooth and gradual change (see Fig. 5). However, when stress in the FRP is transferred to the free end, end slip occurs and this boundary condition makes the strain in the FRP at that location decrease suddenly to zero (see Fig. 5). Rather high strains in the FRP can be observed even at locations very close to the free end, implying that there is high bond stress within a short distance from the free end (see Fig. 5). It is noted that successful recording of strain distributions in the FRP near the free end is difficult since the macro-debonding process toward the free end in a pullout test is very rapid. The brittle interface fracture mechanism is different from that of reinforcement in concrete. An analytical solution to demonstrate different $\tau \sim S$ behaviors of the FRP-concrete interface near the free end in a pullout test, is given as follows. It is assumed, as shown in Eq. 12, that a unified $\tau \sim \mathcal{\varepsilon \sim S}$ expression like Eq. 11 can be applicable for the FRP-concrete interface as well to describe the different natures of strain distribution in the FRP near and far from the free end (see Fig. 5).

$$
\begin{aligned}
& \tau=g(\varepsilon) \tau_{0}(s)=2 G_{f} B(\exp (-B s)-\exp (-2 B s)) \\
& =2 G_{f} B \exp (-B s)(1-\exp (-B s))
\end{aligned}
$$

As a result, the problem in the current analysis is how to get expressions for $g(\varepsilon)$ and $\tau_{0}(s)$. From Eq. 4, which is true for the boundary condition of $\varepsilon=0, s=0$ and $\tau=0$ (long bond length case), it follows that:

$$
\begin{aligned}
& \frac{\varepsilon}{A}=1-\exp (-B s) \\
& \therefore \exp (-B s)=1-\frac{\varepsilon}{A}
\end{aligned}
$$

As a consequence, the function for FRP strain, $g(\varepsilon)$ is assumed as follows:

$$
g(\varepsilon)=1-\frac{\varepsilon}{A}
$$

Substituting Eqs. 13 and 14 into Eq. 12,

$$
\tau=g(\varepsilon) \tau_{0}(s)=2 G_{f} B g(\varepsilon)(1-\exp (-B s))
$$

$$
\therefore \tau_{0}(s)=2 G_{f} B(1-\exp (-B s))
$$




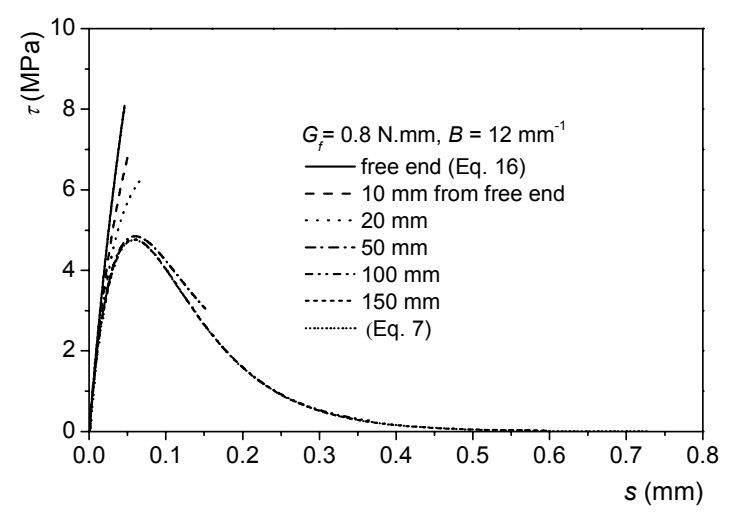

Fig. 6 Obtained $\tau \sim s$ relationships at different locations from free end based on Eq.15.

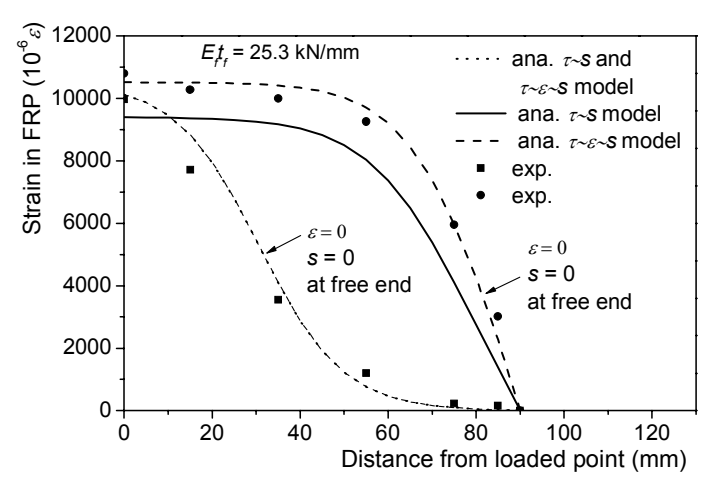

Fig.7 Strain distributions in FRP predicted by $\tau \sim s$ and $\tau \sim \varepsilon \sim s$ models at different peeling stages.

According to the obtained $\tau \sim \mathcal{E} \sim S$ expression Eq. 15, Fig. 6 presents the $\tau \sim s$ models at different locations from the free end in a pullout test $\left(G_{f}=0.8 \mathrm{~N} / \mathrm{mm}\right.$ and $B=12$ $\mathrm{mm}^{-1}$ are assumed). Local $\tau \sim s$ models at distances greater than $100 \mathrm{~mm}$ from the free end show practically no difference. In other words, the occurrence of slip at the free end does not affect $\tau \sim s$ models at locations far away from the free end. Under this circumstance, the $\tau \sim s$ model and $\tau \sim \mathcal{E} \sim S$ model become the same and strain effects do not exist. However, strain effects become noticeable at a distance shorter than $50 \mathrm{~mm}$ from the free end. Particularly higher peak bond stress can be achieved at the location of 0 to $20 \mathrm{~mm}$ far away from the free end in a pullout test.

Figure 7 compares experimentally observed and analytical strain distributions in FRP $\left(E_{f} t_{f}=25.3 \mathrm{kN} / \mathrm{mm}\right)$ at different peeling stages in a pullout test of the FRP-concrete interface with the bond length of $90 \mathrm{~mm}$. It is indicated that the predicted strain distributions by the $\tau \sim S$ and $\tau \sim \mathcal{E} \sim S$ models are the same when the pullout force in FRP has not been transferred to the free end, in other words, when the interface maintains the boundary condition of zero strain and zero slip (or very small slip) at the free end. However, when the pull out force is transferred to the free end and slip occurs as a consequence, only the $\tau \sim \mathcal{E} \sim S$ model (Eq. 15) can explain well the experimentally observed high strain in FRP near the free end.

The difficulty in getting the whole $\tau \sim S$ relationships at the location very near to the free end during a pullout test should be mentioned here. It is impossible to know the peak interface stress at the free end where strain in FRP always remains exactly zero. More experimental evidence based on improved measuring techniques might be necessary to further verify experimentally how FRP strains affect the local $\tau \sim S$ behaviors near the free end. Nevertheless, introduction of the $\tau \sim \mathcal{E} \sim S$ model at least can help us understand that applying different bond lengths in a pullout test may change the configuration of the $\tau \sim \mathrm{s}$ model. The closer the bond location to the free end and the shorter the bond length used in pullout tests, the more brittle behaviors the $\tau \sim S$ models have (see Fig. 7). Obtaining stable $\tau \sim \mathrm{s}$ models with whole softening branches requires a long enough bond length.

\section{Analytical approach for developing effective bond length model}

An important interfacial parameter termed effective bond length is needed for anchorage design of FRP-concrete interfaces. In order to define the effective bond length in a comprehensive way, we need to have a good understanding of strain distributions in externally bonded FRP or shear stress distributions along the interfaces. The following differential equation has been popularly used by many researchers to perform stress analysis in bonded connections subjected to shear by neglecting the bending effects of FRP, interfacial normal stress and strain in concrete (e.g. Brosens and Van Germert 1998, Lorenzis et al. 2001, Wu et al. 2002, Yuan et al. 2004):

$$
\frac{d^{2} s(x)}{d x^{2}}-\frac{\tau(x)}{E_{f} t_{f}}=0
$$

Equation 17 can be rewritten as the following equation with substitution of the bond stress-slip model (Eq. 7):

$$
\frac{d^{2} s(x)}{d x^{2}}=\frac{2 B G_{f}}{E_{f} t_{f}}(\exp (-B s)-\exp (-2 B s))
$$

With a long bond length $L$ as shown in Fig. 1, the solution for Eq. 18 can be obtained as follows (see details in Appendix I):

$$
s(x)=\frac{1}{B} \ln \left[\exp B\left(A x+c_{2}\right)+1\right]
$$




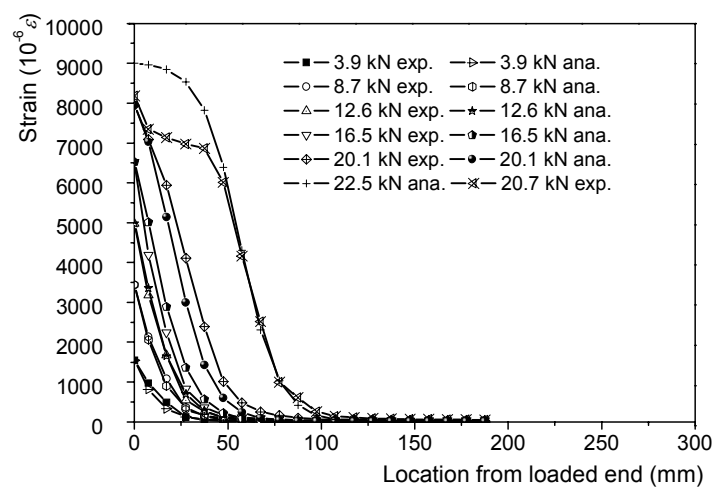

(a)

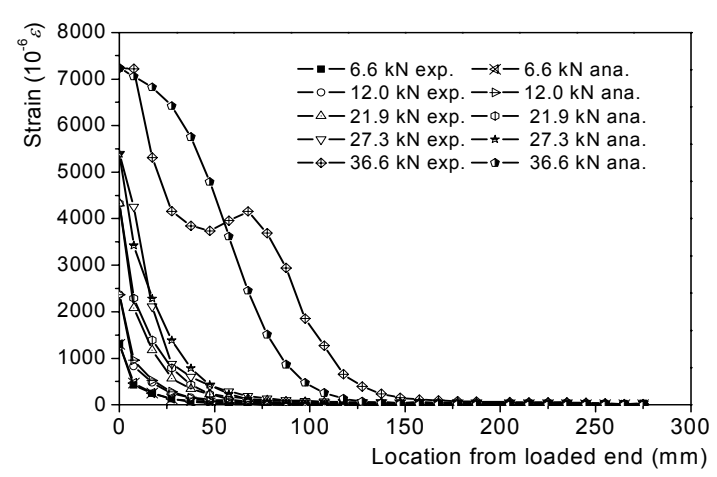

(b)

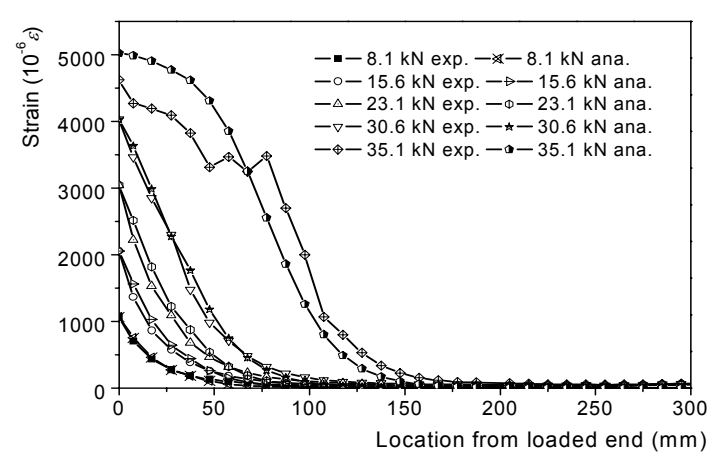

(c)

Fig. 8 Comparison between experimental and analytical distributions in FRP: (a) FRP stiffness: $25.3 \mathrm{kN} / \mathrm{mm}(1$ layer of FRP sheet); (b) FRP stiffness: $50.6 \mathrm{kN} / \mathrm{mm}$ (2 layers of FRP sheets); (c) FRP stiffness: $75.9 \mathrm{kN} / \mathrm{mm}$ (3 layers of FRP sheets).

Therefore, the strain distribution in FRP can be written as:

$$
\varepsilon(x)=\frac{d s(x)}{d x}=A \frac{\exp B\left(A x+c_{2}\right)}{\exp B\left(A x+c_{2}\right)+1}
$$

where $A=\sqrt{2 G_{f} / E_{f} t_{f}}$, and $c_{2}=$ constant related to the boundary condition at the loaded end.

When pullout force $P$ is exerted at the loaded end, the boundary condition of $\varepsilon=P /\left(b_{f} E_{t} t_{f}\right)$ at $x=L$ can be introduced into Eq. 20, and the constant $c_{2}$ can be determined as follows:

$$
c_{2}=\frac{\ln \frac{P}{P_{\max }-P}}{B}-A L
$$

where $P_{\max }=$ theoretical maximum pullout force (Eq. 8).

By substituting Eq. 21 into Eq. 20, the strain distribution of FRP sheets under pullout load $P$ and a long bond length $L$ can be expressed as:

$$
\varepsilon(x)=\frac{A}{1+\frac{\exp (A B(L-x))\left(P_{\max }-P\right)}{P}}
$$

Figure 8. a to Fig. 8. c shows comparisons between experimental strain distributions in FRP (Dai et al. 2002) and analytical ones from Eq. 22. The rather good agreement indicates that prediction on strain distribution in FRP based on Eq. 22 and the proposed $\tau \sim s$ model is reliable.

Subsequently, shear stress distribution in the bond layer can be obtained as follows:

$$
\tau(x)=\frac{E_{f} t_{f} P A^{2} B\left(P_{\max }-P\right) \exp (A B(L-x))}{\left[P+\left(P_{\max }-P\right) \exp (A B(L-x))\right]^{2}}
$$

To define effective bond length, Fig. 9 and Fig. 10 show the strain distributions in FRP and interfacial shear stress distributions along an FRP-concrete interface with a bond length of $400 \mathrm{~mm}$ under different pullout loads based on Eqs. 22 and 23 (FRP stiffness of $50.6 \mathrm{kN} / \mathrm{mm}$ is used as a common case in practice). The bond area where the strains in FRP sheets have noticeable values can be seen in Fig. 9 to extend towards the free end of the interface with increasing pullout loads. However, even if the pullout load increases to $99.99 \%$ of the theoretical maximum pullout load, FRP strains are visible only along the $200 \mathrm{~mm}$ long bond area. The areas with small

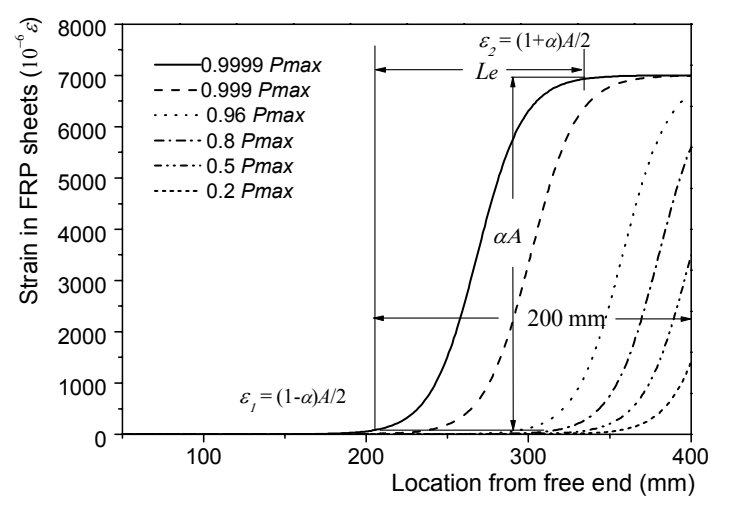

Fig. 9 Strain distributions in FRP under different pullout forces. 


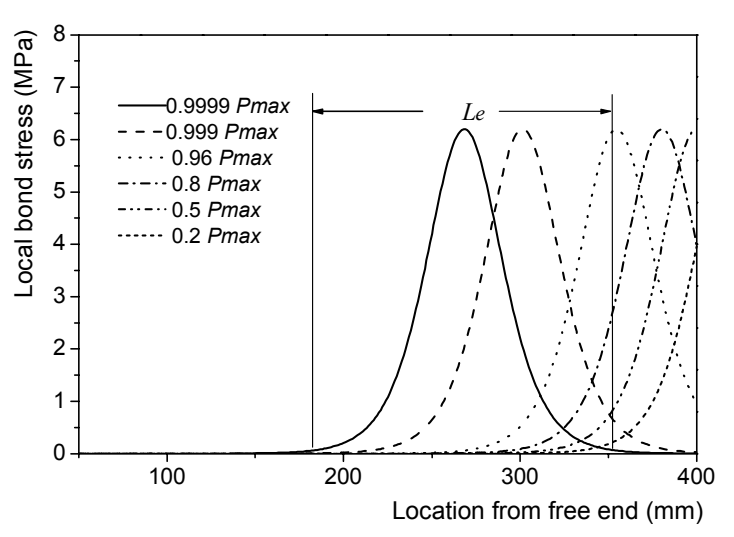

Fig. 10 Bond stress distributions along interface under different pullout forces.

strains in the FRP cannot transfer the shear bond stress actively (see the area near the free end in Fig. 10). Therefore, bond lengths beyond $200 \mathrm{~mm}$ can hardly increase the ultimate pullout load. On the other hand, the bond area near the loaded end where FRP has very high strain extends gradually with continual increases in pullout load. However, the gradient of strain distributions at that location becomes very small due to interfacial debonding, meaning that shear bond stress at that location becomes almost inactive as well (see shear bond stress distribution near the loaded end at the pullout load of $0.9999 \mathrm{P}_{\max }$ in Fig. 10). Obviously, the effective bond length $L_{e}$ of an FRP-concrete interface can be defined as an active bond zone, which bears shear stresses most efficiently, as shown in Fig. 10. Stress transferred outside the defined zone is regarded as negligible because slips between the FRP and concrete over that location are too small or too large to produce bond stress actively. Mathematically, $L_{e}$ can be expressed as a distance between two locations $x_{1}$ and $x_{2}\left(L_{e}=x_{2}-x_{1}\right)$, which bears the pullout force $\alpha P_{\max }$ ( $\alpha$ can be taken as a constant that is nearly equal to one) as shown in Fig. 9. At these two locations, strains of FRP are calculated as follows:

$$
\varepsilon_{1}=\frac{1-\alpha}{2} A ; \varepsilon_{2}=\frac{1+\alpha}{2} A ; \varepsilon_{1}-\varepsilon_{2}=\alpha A
$$

The following equation can be obtained from Eq. 22:

$$
L-x=\frac{1}{A B}\left[\ln \left(\frac{A}{\varepsilon(x)}-1\right)-\ln \left(\frac{P_{\max }-P}{P}\right)\right]
$$

By substituting Eq. 25 into Eq. 24, the effective bond length can be obtained as follows:

$$
\begin{aligned}
& L_{e}=x_{2}-x_{1}=\left(L-x_{1}\right)-\left(L-x_{2}\right) \\
& =\frac{2}{A B} \ln \left(\frac{1+\alpha}{1-\alpha}\right)=\frac{\sqrt{2 E_{f} t_{f}}}{B \sqrt{G_{f}}} \ln \left(\frac{1+\alpha}{1-\alpha}\right)
\end{aligned}
$$

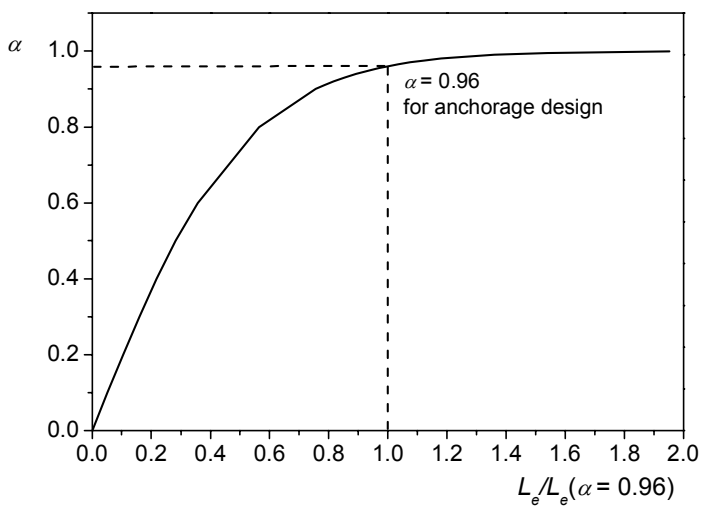

Fig. 11 Relationship between $\alpha$ and $L_{e}$.

Figure 11 shows the relationship between $\alpha$ and $L_{e}$. The value $\alpha$ increases less and less efficiently as the $L_{e}$ increases. In other words, with gradual increase in bond length, the load transfer capacity that can be carried increases less and less efficiently. Due to the configured shape of the presently employed $\tau \sim s$ model, tiny shear stress always exists in the bond interface even if the interfacial slip is very large (see Fig. 3), meaning that the theoretical maximum pullout load of an FRP-concrete interface corresponds with an indefinitely long bond length. For a reasonable anchorage strength design, use of the constant 0.96 for $\alpha$ in Eq. 26 (Ueda and Dai, 2004) is suggested. It should be noted that a bond length longer than the defined anchorage length cannot increase the bond strength efficiently (see Fig. 11, in which $\alpha$ can be regarded as an index related to the bond force carrying capacity achieved by the active bond length as mentioned above). However, this permits progressive development of interfacial debonding, resulting in greater interfacial ductility.

It can be seen in Eq. 26 that the effective bond length increases with decreases in $B$ and $G_{f}$. Usually soft adhesives correspond with small $B$ and poor bonding quality leads to low $G_{f}$. Both result in longer effective bond length. Therefore, through the use of parameters $G_{f}$ and $B$, consideration of the effects of adhesives and overall bonding quality on anchorage length becomes possible. All the other existing models listed in Table 1, however, only can show the effects of concrete strength and FRP stiffness on the effective bond length.

For commonly used adhesives, the authors suggested the use of $0.514 f_{c}{ }^{0.236}$ and 10.4 as reference values for $G_{f}$ $(\mathrm{N} / \mathrm{mm})$ and $B\left(\mathrm{~mm}^{-1}\right)$, respectively, based on a large number of experiments (Dai et al. 2005). Therefore, Eq. 26 can be simplified as:

$$
L_{e}=\frac{\sqrt{2 E_{f} t_{f}}}{10.4 \sqrt{0.514 f_{c}^{0.236}}} \ln \left(\frac{1.96}{0.04}\right)=0.74 \sqrt{\frac{E_{f} t_{f}}{f_{c}^{0.236}}}
$$

Comparisons between the present and 5 other existing effective bond length models are shown in Fig. 12. Although three models (Neubauer and Rostásy 1997, Chen 


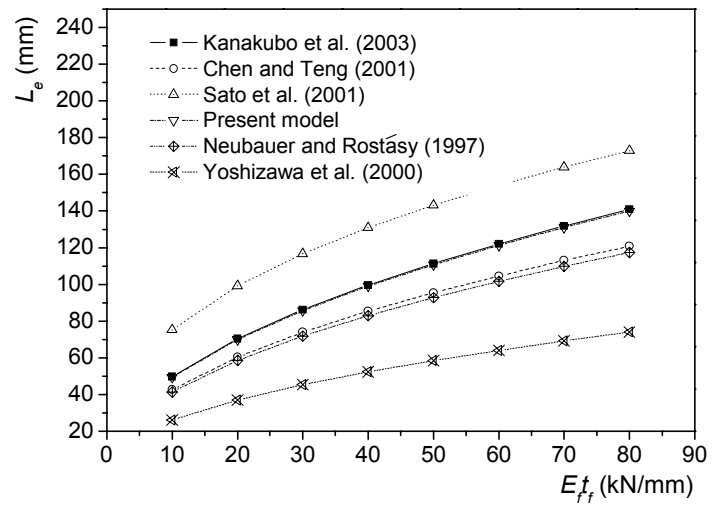

Fig. 12 Comparisons among different effective bond length models.

and Teng 2001, Kanakubo 2003) and the present model give close prediction, significant differences still exist among all these models in a general sense. These differences may be caused by different bonding processes or bonding materials applied by different researchers because even commonly used adhesives may have noticeable differences in mechanical properties, workability, etc. There are many types of bonding materials used in practical cases, whereas unfortunately only limited attention has been paid to quantitative comparisons among all existing bonding materials. Although the authors concluded that soft adhesives usually lead to higher $G_{f}$ but lower $B$ and vice versa (Dai et al. 2005), further data collection is necessary to formulate unified expressions for $G_{f}$ and $B$ that are suitable for all commercially available bonding materials. A yet even more important task may be to provide a general analytical solution like Eq. 26, which can be suitable for analyzing FRP-concrete interfaces with any adhesives' properties. Engineers and researchers can determine needed parameters $G_{f}$ and $B$ easily from pullout tests.

\section{Development of unified bond strength model}

When the bond length is shorter than the effective bond length, the bond strength of FRP-concrete interfaces significantly changes with the bond length. Most of the existing models use two equations to predict the bond strength of FRP-concrete interfaces for short and long bond lengths, respectively (see Table 1). The effective bond length is usually used in the bond strength model as a parameter, meaning that the accuracy of the bond strength model is dependent on the manner in which the effective bond length is determined, which may in fact differ greatly among different models. It is theoretically possible to predict the bond strength of an FRP-concrete interface under any boundary condition (either long or short bond length) through FEM or other numerical solutions if the corresponding local $\tau \sim s$ model is known. However, for practical engineering design purposes, a closed-form expression is preferable. At present, a simple bilinear bond stress-slip model is most commonly used. One possible reason may be the ease it offers for conducting closed-form analysis. For the present non-linear $\tau \sim S$ model, a comprehensive bond strength model can be proposed based on a simple assumption.

As shown in Fig. 9, a load with the value of $\alpha P_{\max }$ can be transferred within the most active bond area, that of effective bond length $L_{e}$ (Eq. 26). For an FRP-concrete interface with shorter bond length $L_{b}$, all the bond length becomes efficient or active to deliver the ultimate pullout load $P_{u}$. Therefore, it can be assumed that $P_{u}$ can be calculated as $\alpha P_{\max }$, in which $\alpha$ is obtained from Eq. 26 by substituting $L_{e}$ with $L_{b}$. Here, $P_{\max }$ is the theoretical maximum bond force for an FRP-concrete interface with a long enough bond length, which is given by Eq. 8 . Therefore, with the substitution of $L_{e}=L_{b}$, Eq. 26 can be rewritten as follows:

$$
\alpha=\frac{\exp \left(\frac{L_{b} B \sqrt{G_{f}}}{\sqrt{2 E_{f} t_{f}}}\right)-1}{\exp \left(\frac{L_{b} B \sqrt{G_{f}}}{\sqrt{2 E_{f} t_{f}}}\right)+1}
$$

The expression for bond strength of an FRP-concrete interface with a given bond length of $L_{b}$ can be written as:

$$
P_{u}=\alpha P_{\max }
$$

The bond witdth of externally bonded FRP used for pullout tests influences achieved average bond strength as well as the calibration of the interface fracture energy $G_{f}$ To consider the effects of FRP's width used in tests and to keep the calibrated $G_{f}$ independent of that width, the expression for $P_{\max }$ (Eq. 8) has been modified as follows (Dai et al. 2005):

$$
P_{\max }=\left(b_{f}+2 \Delta b_{f}\right) \sqrt{2 E_{f} t_{f} G_{f}}
$$

where $\Delta b_{f}=3.7 \mathrm{~mm}$.

\section{Experimental validation}

For validation of the unified bond strength model (Eqs. 28 to 30), single lap pullout bond tests for FRP-concrete interfaces with different FRP stiffness $(25.3 \mathrm{kN} / \mathrm{mm}$, $50.6 \mathrm{kN} / \mathrm{mm}$ and $75.9 \mathrm{kN} / \mathrm{mm}$ ) and different bond length (from $20 \mathrm{~mm}$ to $300 \mathrm{~mm}$ ) were carried out (Dai 2003). The test results are shown in Table 2. Series 1, 2 and series 3, 4 specimens in Table 2 were not cast at the same time and the bond strength per unit width of series 3 specimens is found to be a bit lower than that of series 2 specimens although they share the same test variables. That difference may be due to construction deviations during preparation of the specimens. Therefore, for each 
Table 2 Bond strength of FRP-concrete interfaces obtained from single lap pullout bond tests.

\begin{tabular}{|c|c|c|c|c|c|c|c|c|c|}
\hline $\begin{array}{l}\text { No. of speci- } \\
\text { mens }\end{array}$ & $\begin{array}{c}f_{c}^{\prime} \\
(\mathrm{MPa})\end{array}$ & $\begin{array}{c}\text { Layers of } \\
\text { FRP sheets }\end{array}$ & $\begin{array}{c}E_{f} t_{f} \\
(\mathrm{kN} / \mathrm{mm})\end{array}$ & $\begin{array}{c}L_{b} \\
(\mathrm{~mm})\end{array}$ & $\begin{array}{c}b_{f} \\
(\mathrm{~mm})\end{array}$ & $\begin{array}{c}P_{u} \\
(\mathrm{kN})\end{array}$ & $\begin{array}{c}P_{u} / b_{f} \\
(\mathrm{kN} / \mathrm{mm})\end{array}$ & $P_{u} / P_{\max }$ & Note \\
\hline C-1-50 & \multirow{4}{*}{35.0} & \multirow{4}{*}{1} & 25.3 & 50 & 100 & 24.3 & 0.24 & 0.95 & \multirow{4}{*}{ Series 1} \\
\hline C-1-100 & & & 25.3 & 100 & 100 & 25.3 & 0.25 & 1.00 & \\
\hline C-1-150 & & & 25.3 & 150 & 100 & 25.4 & 0.25 & 1.00 & \\
\hline C-1-200 & & & 25.3 & 200 & 100 & 24.9 & 0.25 & 0.98 & \\
\hline C-2-50 & \multirow{4}{*}{35.0} & \multirow{4}{*}{3} & 75.9 & 50 & 100 & 34.5 & 0.35 & 0.82 & \multirow{4}{*}{ Series 2} \\
\hline C-3-100 & & & 75.9 & 100 & 100 & 40.5 & 0.41 & 0.96 & \\
\hline C-3-150 & & & 75.9 & 150 & 100 & 42.0 & 0.42 & 1.00 & \\
\hline C-3-300 & & & 75.9 & 300 & 100 & 38.4 & 0.38 & 0.91 & \\
\hline C-3-20 & \multirow{5}{*}{32.8} & \multirow{5}{*}{3} & 75.9 & 20 & 50 & 4.6 & 0.09 & 0.28 & \multirow{5}{*}{ Series 3} \\
\hline C-3-40 & & & 75.9 & 40 & 50 & 11.2 & 0.22 & 0.69 & \\
\hline C-3-80 & & & 75.9 & 80 & 50 & 15.6 & 0.31 & 0.96 & \\
\hline C-3-150 & & & 75.9 & 150 & 50 & 16.2 & 0.32 & 1.00 & \\
\hline C-3-300 & & & 75.9 & 300 & 50 & 16.2 & 0.32 & 1.00 & \\
\hline C-2-20 & \multirow{4}{*}{32.8} & \multirow{4}{*}{2} & 50.6 & 20 & 50 & 4.5 & 0.09 & 0.31 & \multirow{4}{*}{ Series 4} \\
\hline C-2-40 & & & 50.6 & 40 & 50 & 7.9 & 0.16 & 0.55 & \\
\hline C-2-60 & & & 50.6 & 60 & 50 & 13.7 & 0.27 & 0.95 & \\
\hline C-2-200 & & & 50.6 & 200 & 50 & 14.4 & 0.29 & 1.00 & \\
\hline
\end{tabular}

independent test series, experimentally obtained pullout forces of FRP-concrete interfaces are normalized by the maximum pullout force obtained in that series for the convenience of comparing all series together. Then all experimentally obtained bond strengths of FRP-concrete interfaces with different bond length and FRP stiffness are plotted in Fig. 13. The bond strengths predicted by the proposed model (Eqs. 28 to 30 ) are also given in the figure. The simplified closed-form model (Eqs. 28 to 30) can be seen to predict the bond force capacity of FRP-concrete interfaces with either long or short bond length with acceptable accuracy. The unified bond strength model is also dependent on only two parameters, interfacial fracture energy $G_{f}$ and interfacial ductility factor $B$, which can be calibrated through simple pullout tests. By using the unified model, it is not necessary to build two separate bond strength models by judging whether or not the bond length is longer than the effective bond length as required in the case of the existing models (see Table 1).

Special attention should be paid to large scatter of bond strength of FRP-concrete interfaces. The authors collected a large number of pullout bond test results for FRP-concrete interfaces (220 specimens), which were published by 11 researchers (Chajes et al. 1996, Täljsten 1997, Ueda et al. 1999, Brosens and Van Gemert 1999, Bizindavyi and Neale 1999, Sato et al. 2001, Gabriel et al. 2000, Yoshizawa et al. 2000, Lorenzis et al. 2001, Nakaba et al. 2001, Dai et al. 2002). Figure 14 shows a comparison between all these test results and analytical ones predicted using the present bond strength model, with $0.514 f_{c}^{\prime 0.236}$ and 10.4 as the reference values for $G_{f}$ $(\mathrm{N} / \mathrm{mm})$ and $B\left(\mathrm{~mm}^{-1}\right)$, respectively. Scatter of bond strength of FRP-concrete interfaces is shown to be rather large even though the present model gives acceptable accuracy at an average level. The large scatter may be caused by variations in concrete treatment processes, bonding techniques, and most possibly (both mechanical and geometrical) properties of bonding materials used in different laboratories or construction fields. Of course, in order to fill in the gaps among all experimental data for a safe design, a reduction factor 0.68 can be added in the present bond strength model (Eqs. 28 to 30 ) if we allow $5 \%$ of experimental data (points above the dotted line $P_{\text {pre. }} / P_{\text {ana. }}=1.5$ in Fig. 14) to be overestimated. Alternately, according to the square root relationship between

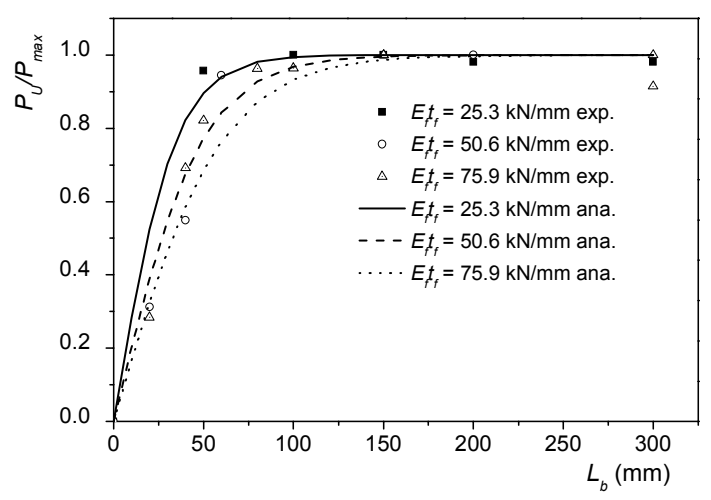

Fig. 13 Change of bond strength with bond length. 


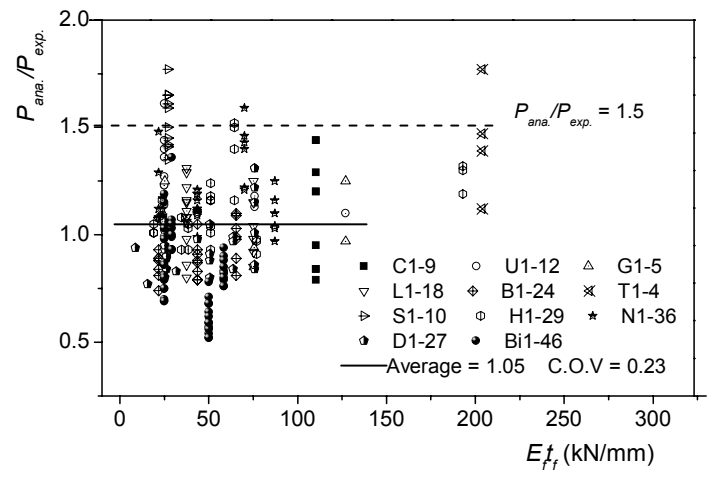

Fig. 14 Comparison between experimental and analytical bond strengths.

the ultimate pullout load and interfacial fracture energy, a reduction factor of $k_{c}=0.46$ can be assigned to $G_{f}$ for engineering design purposes. With this approach, the anchorage length is assigned a safety factor of 1.46 based on the relationship between $L_{e}$ and $G_{f}$ as shown in Eq. 26. It also can be seen from Fig. 14 that the present model overestimates few test data for FRP-concrete interfaces with very high tension stiffness of FRP (about 200 $\mathrm{kN} / \mathrm{mm}$ ), implying that FRP-concrete joints that use very thick FRP possibly result in small interfacial fracture energy. Since the average level and scatter is dependent on the experimental outlook, to narrow down the large reduction factors needed, engineers or researchers can determine by themselves the values of $G_{f}$ and $B$, which can be easily calibrated through standard pullout tests. All other bonding characteristics needed for design or analysis can be calculated through general analytical models developed in this paper.

\section{Concluding remarks}

Clarifying the bond characteristics of the interface between concrete and externally bonded FRP sheets/strips is essential for FRP external strengthening design of concrete structures. Pullout tests are usually applied to obtain bond characteristics of FRP-concrete interfaces in terms of overall or local interfacial bond properties. This paper introduces unified analytical approaches showing how to extract all the bond characteristics necessary for engineering design and numerical analysis from conventional pullout tests of FRP-concrete interfaces.

A good understanding of the interfacial bond stress-slip model makes it possible to develop models for predicting the anchorage length and the interface bond strength in a rigorous and general way. By using the non-linear bond stress-slip model, which was proposed in a previous study of the authors (Dai et al 2005), with two simple parameters named interfacial fracture energy $G_{f}$ and interfacial ductility index $B$, this paper has developed unified bond strength and effective bond length models for FRP-concrete interfaces through the analysis of characteristics of strain distributions in FRP and bond stress distributions along the interface in pullout tests for
FRP-concrete interfaces. The present analytical approaches link successfully all bonding characteristics necessary for engineering design and interface numerical analysis to two simple bonding parameters, $G_{f}$ and $B$, which can be calibrated easily through standard pullout tests. A bond stress-slip-strain model, in which effects of FRP strain on the bond stress-slip relationship is considered, explains the differences in local bond stress-slip models and the nature of strain distribution appearing in different bond locations from the load or free end in a pullout test.

Despite their simplicity in terms of using two parameters only, the present models for the first time make it possible to include the properties of adhesives in bond analysis of FRP-concrete interfaces. The overall interface property is represented using interface fracture energy instead of concrete strength. The use of another interfacial ductility index $B$ in combination with $G_{f}$ can represent changes in interface shear stiffness during the non-linear interface peeling stages. The combination of these two factors can be used to consider the contribution of the adhesive bond layer. All other existing bond models hardly can consider the effects of adhesives in their bond stress-slip relationships, bond strength and effective bond length predictions since they are linked to mechanical properties of FRP and concrete only. Thus the present unified approaches are considered by the authors to have greater generality.

Appendix I: Solution for the interfacial differential equation (Eq. 18)

The interfacial differential equation is:

$$
\frac{d^{2} s(x)}{d x^{2}}=\frac{2 B G_{f}}{E_{f} t_{f}}(\exp (-B s)-\exp (-2 B s))
$$

Using $\varepsilon=\frac{d s}{d x}$, Eq. A1 can be rewritten as:

$$
\begin{aligned}
& \varepsilon d \varepsilon=\frac{G_{f}}{E_{f} t_{f}} d(1-\exp (-B s))^{2} \\
& \therefore \int \varepsilon d \varepsilon=\frac{G_{f}}{E_{f} t_{f}} \int d(1-\exp (-B s))^{2} \\
& \therefore \varepsilon^{2}=\left(\frac{d s}{d x}\right)^{2}=\frac{2 G_{f}}{E_{f} t_{f}}(1-\exp (-B s))^{2}+c_{1}
\end{aligned}
$$

$$
\int \frac{d s}{\sqrt{\frac{2 G_{f}}{E_{f} t_{f}}(1-\exp (-B s))^{2}+c_{1}}}=\int d x
$$


There exists the following boundary condition when a long bond length $L$ (see Fig. 1) is used in the pullout test:

$$
\left.\varepsilon(x)\right|_{x=0}=\left.\frac{d s(x)}{d x}\right|_{x=0}=0,\left.s(x)\right|_{x=0}=0
$$

With the substitutions of Eq. A6 into Eq. A5, $c_{1}=0$ can be obtained and Eq. A5 can be rewritten as follows:

$$
\begin{aligned}
& \frac{d s}{1-\exp (-B s)}=A d x, A=\sqrt{\frac{2 G_{f}}{E_{f} t_{f}}} \\
& \therefore \frac{1}{B} \int d \ln (\exp (B s)-1)=A \int d x \\
& \therefore \frac{1}{B} \ln (\exp (B s)-1)=A x+c_{2} \\
& \therefore \quad s(x)=\frac{1}{B} \ln \left[\exp B\left(A x+c_{2}\right)+1\right]
\end{aligned}
$$

\section{References}

Bizindavyi, L. and Neale, K. W. (1999). "Transfer length and bond strength for composites bonded to concrete", Journal of Composites for Construction, ASCE, 3(4), 153-160.

Brosens K, Van Germert D. (1998). "Plate end shear design for external CFRP laminate", Proceeding of FRAMCOS-3, Gifu, Japan, 1793-1804.

Brosens, K. and Van Gemert, D. (1999). "Anchorage design for externally bonded carbon fiber reinforced polymer laminates", $A C I, S P$ 188-56, 635-641.

Buyukozturk, O., and Hearing B. (1998). "Fracture behavior of precracked concrete beams retrofitting with FRP", Journal of Composites for Construction, ASCE, 2 (3), 138-144.

Buyukozturk, O., Gunes, O., and Karaca, E. (2004). "Progress on understanding problems in reinforced concrete and steel members strengthened using FRP composites", Construction and Building Materials, 18. 9-19.

Chajes, M. J., Finch, William. W., Januszka, T. F. and Thomson, T. A. (1996). "Bond and force transfer of composite material plates bonded to concrete", $A C I$ Structural Journal, 93 (2), 208-217.

Chen, J. F. and Teng, J. G. (2001). "Anchorage strength models for FRP and steel plates bonded to concrete." Journal of Structural Engineering, ASCE, 127 (7), 784-791.

Chen J. F., Teng J. G. (2003). "Shear capacity of FRP-strengthened RC beams: FRP debonding", Construction and Building Materials, 17 (1), 27-41.

Dai, J. G., Sato, Y. and Ueda, T. (2002). "Improving the load transfer and effective bond length for FRP composites bonded to concrete." Proceedings of the Japan Concrete Institute, 24, 1423-1428.

Dai, J. G. (2003). "Interfacial models for fiber reinforced polymer (FRP) sheets externally bonded to concrete." $\mathrm{Ph}$. D dissertation, Hokkaido University, Japan.

Dai, J. G., Sato, Y., and Ueda, T. (2005). "Development of nonlinear bond stress slip model with a simple method." Journal of Composite for Construction, ASCE, 9 (1), 52-62.

Externally Bonded FRP Reinforcement for RC Structures, fib bulletin 14 TC Report, 2001.

Gabriel S. (2000). "Model for shear resisting capacity of reinforced concrete columns strengthened with carbon fiber sheets." Doctoral dissertation, Hokkaido University.

Karbhari, V.M. and Engineer, M. (1996). "Investigation of bond between concrete and composites: Use of a Peeling Test." Journal of Reinforced Plastics and Composites, 15, 208-227.

Kamiharako A., Shimomura T., Maruyama K. (2001). "Evaluation method for shear capacity of RC members retrofitted with externally bonded continuous fiber sheet", JSCE, Concrete Library International, 37, 147-160.

Kanakubo, T., Furuta, T., and Fukuyama, H. (2003). "Bond strength between fiber-reinforced polymer laminates and concrete. ", Proceedings of FRPRCS-6, Edited by K. H Tan, Singapore, 8-10 July 2003, 134-143.

Khalifa A.; Gold, W.; Nanni., A, and Abel-Aziz M. I. (1998). "Contribution of externally bonded FRP to the shear capacity of RC flexural members", Journal of Composites for Construction, ASCE, 2 (4), 195-202.

Li, V. C. and Ward, R. J. (1989). "A novel testing technique for post-peak tensile behaviors of cementitious materials", Fracture Toughness and Fracture Energy, Balkema, 193-195.

Lorenzis, L. De., Miller, B., and Nanni, A. (2001). "Bond of fiber-reinforced polymer laminates to concrete", ACI Material Journal, 98 (3), 256-264.

Maeda, T., Asano, Y., Sato, Y., Ueda, T., and Kakuta, Y. (1997). "A study on bond mechanism of carbon fiber sheet." Non-Metallic (FRP) Reinforcement for Concrete Structures, Proceedings of Third International Symposium, 1, 279-286.

Miller, B. and Nanni, A. (1999). "Bond between CFRP sheets and concrete." Proc. of ASCE 5th Materials Congress, Edited by L. C. Bank, Cincinnati, OH, 240-247.

Nakaba, K., Kanakubo, T., Furuta, T. and Yoshizawa, H. (2001). "Bond behavior between fiber-reinforced polymer laminates and concrete", ACI Structural Journal, 98 (3), 359-167.

Neubauer, U., and Rostásy, F. S. (1997). “Design aspects of concrete structures strengthened with externally bonded CFRP plates." Proceedings of 7th International Conference on Structural Faults and Repairs, ECS Publications, Edinburg, Scotland, 2, 
109-118.

Recommendations for Upgrading of Concrete Structures with Use of Continuous Fiber Sheets, JSCE, Concrete Library, 2000, 7.

Santos, A. C. Dos., Bittencourt T. N. and Gettu, R. (2003). "Experimental analysis of interface between CFRP and concrete using cylindrical specimens.", Proceedings of FRPRCS-6, Edited by K. H Tan, Singapore, 183-182.

Sato, Y. and Vecchio, Frank J. (2003). "Tension stiffening and crack formation in reinforced concrete members with fiber-reinforced polymer sheets", ASCE, Journal of Structural Engineering, 129 (6), 717-724.

Sato, Y., Asano, Y. and Ueda, T. (2001). "Fundamental study on bond mechanism of carbon fiber sheet", Concrete Library International, JSCE, 37, 97-115.

Sato, Y., Kimura, K. and Kobatake, Y. (1997). "Bond behaviors between CFRP sheet and concrete", Journal of Structural Construction Engineering, AIJ, No.500, 75-82. (in Japanese)

Sebastian W. M. (2001). "Significance of mid-span debonding failure in FRP-plated concrete beams", Journal of Structural Engineering, ASCE, 127 (7), July 2001.

Shima, H., Chou, L. and Okamura, H. (1987). "Micro and Macro Models for Bond in Reinforced Concrete.", Journal of the Faculty of Engineering, The University of Tokyo (B), 39 (2).

Smith S. T. and Teng J. G. (2002). FRP-strengthened RC beams. I: Review of debonding strength models, Engineering Structures, 24 (4), 385-395.

Täljsten, B. (1996). "Strengthening of concrete prisms using the plate-bonding technique." International Journal of Fracture, 82, 253-266.

Täljsten B. (1997). "Defining anchor lengths of steel and CFRP plates bonded to concrete", International Journal of Adhesion and Adhesives, 17 (4), 319-327.

Teng, J. G., Smith, S. T., Yao, J. and Chen, J. F. (2003). "Intermediate crack-induced debonding in $\mathrm{RC}$ beams and slabs." Construction and Building Materials, 17,
447-462.

Teng, J. G., Lu, X. Z., Ye, L. P. and Jiang, J. J. (2004). "Bond-slip models for interfaces between externally bonded FRP and concrete", Proceedings of the Second International Conference on FRP Composites in Civil Engineering-CICE 2004, Adelaide, Australia, 55-68.

Triantafillou, T. C. (1999). "Guidelines for the Dimensioning of Reinforced Concrete Elements Strengthened with Sika Carbondur/Sikawrap", University of Patras, Greece.

Ueda, T., Sato, Y. and Asano, Y. (1999). "Experimental study on bond strength of continuous carbon fiber sheet." ACI, SP 188-37, 407-413.

Ueda, T. and Dai, J. G. (2004). "New Shear Bond Model for FRP-Concrete Interface-from modeling to application." Proceedings of the Second International Conference on FRP Composites in Civil Engineering-CICE 2004, Adelaide, Australia, 69-81.

$\mathrm{Wu}, \mathrm{Z}$. and Yin, J. (2003). "Fracturing behaviors of FRP-strengthened concrete structures", Engineering Fracture Mechanics, 70, 1339-1355.

Xiao, J. Z., Li, J. and Zhao, Q. F. (2004). "Experimental study on bond behavior between FRP and concrete", Construction and Building Materials, 18 (10), 745-752.

Yao, J., Teng, J. G. and Chen, J. F. (2004). "Experimental study on FRP-to-concrete bonded joints", Composites, Part B: Engineering, 1-15.

Yoshizawa, H., Wu, Z., Yuan, H. and Kanakubo, T. (2000). "Study on FRP-concrete interface bond performance", Transactions of JSCE, 49 (662), 105-119.

Yokota, M., Shimomura, T., Kamiharako, A. and Maruyama K. (2002). "Influence on mechanical properties of retrofitted member with continuous fiber sheet", Proceedings of the Japan Concrete Institute, 24 (2), 1399-1404. (in Japanese)

Yuan, H., Wu, Z. and Yoshizawa, H. (2001). "Theoretical solutions on interfacial stress transfer of externally bonded steel/composite plates." J. Structural. Mech. Earthquake Eng. JSCE, 18 (1), 27-39. 